\title{
Implementation of a Process-Oriented ISO 9000 and ISO 14000 Management System in a Chemical Manufacturing Site
}

\author{
Stephan Rönninger*
}

\begin{abstract}
Quite often, literature and training courses define how the conversion of an ISO system into a process-oriented system should or could work in theory. By contrast, this is a description of a practical solution implemented in 2001 at our chemical manufacturing site in Switzerland. In summary it can be said that sustainable development leads to a reduction in costs and a reduction in paperwork leaves more time for business. We therefore needed to set up just one simple management system for our tasks of preparing animal feed, food additives, pharmaceuticals and antibiotic products. We have found a way to create an integrated management system which takes account of the different regulations and responsibilities which exist in a large company like Roche, and of different legislations, ISO systems and GMP requirements.
\end{abstract}

Keywords: Chemical manufacturing and ISO - ISO in practice - Management system - Process orientation in a production site

\section{Initial Situation}

We are a production site manufacturing chemical products within the Roche Vitamins Division at which 1200 employees prepare animal feed or food products and premixes, starting materials for cosmetics, active pharmaceutical ingredients (API) and sterile antibiotics. Facilities for storing these kinds of chemicals are also available. We have a quality management system based on the ISO 9000 standard with its 20 chapters, including cGMP requirements. Chapter 21 'Safety' and chapter 22 'Environmental Protection' were added three years ago.

This quality management system was described in a complex handbook containing 187 pages. There were 87 quality guidelines and 110 safety and environmental instructions (called 'SE-Weisungen'), plus 87

\footnotetext{
${ }^{*}$ Correspondence: Dr.-Ing. S. Rönninger

Roche Ltd., Sisseln

Quality Management Specialist

SQQ, building 324/104

Hauptstrasse 4

$\mathrm{CH}-4334$ Sisseln

Tel.: +4162 8662042

Fax: +4162 8662095

E-Mail: stephan.roenninger@roche.com
}

standard operating procedures (SOP) that regulated all work at our site. There was also a flood of new SOPs that was quite hard to manage.

With this mixture of virtually every possible kind of chemical production requirement, we decided we needed to have just one management system covering all relevant points in our business (Fig. 1).
In our opinion, obtaining re-certification to ISO 9001:2000 [1] and certification to ISO 14001:1996 [2] in March 2002 should not be an end in itself. We also wanted a change of philosophy and a switch to process orientation in which all employees share the company's target of synthesizing chemical products and not concentrating on its own organization.

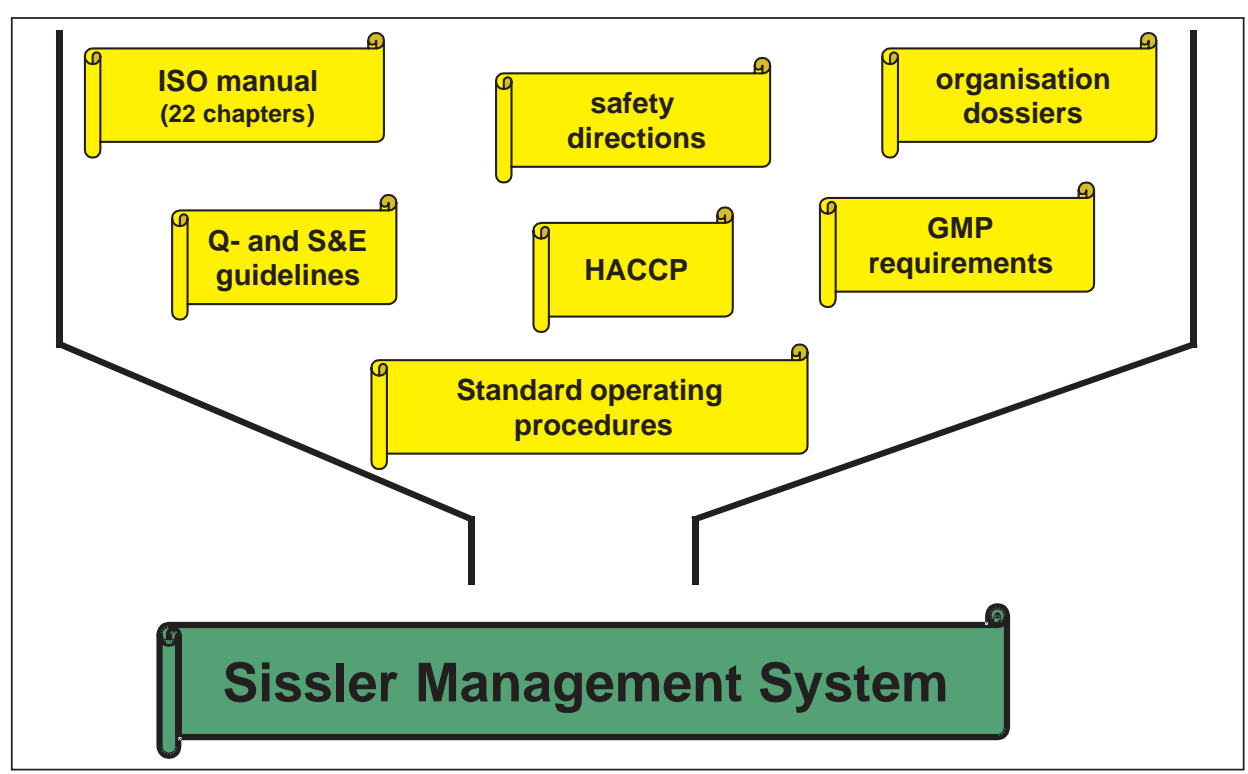

Fig. 1. The way to rearrange our 'quality' management system (funnel) 


\section{The Route to Success}

In most companies the change to a process-oriented ISO system is made by a single member of the quality department, although doing it that way misses the opportunity to make a slight change of philosophy and adopt a totally managed system. By analogy with investment projects, we set up a project team and adopted a fourphase milestone approach to achieve our goals.

\subsection{Preparation Phase}

The supervisor and the key person in the quality department obtained an in-depth knowledge of the new philosophy that the ISO 9000:2000 approach represents at external training courses. They then prepared a preliminary process model for the site. After discussing it with the key person in the environmental department, we submitted a proposal for a project to implement the new philosophy for a radical reorganization of processes. The site management decided to adopt our idea for of having just one, simple combined management system.

\subsection{Executive Project Organization}

The project organization based on middle management was formed. A key person in the quality department was placed in overall charge of the project. We built up a project management team consisting of four persons. The key person in the environmental department was appointed as second project leader in charge of ISO 14000 matters and as leader of one subteam dealing with site management processes. A person from the production plant was made subteam leader responsible for synthesis processes and, finally, a person from the finance department was selected to lead the third subteam dealing with finance, infrastructure and personnel processes (fip management). We thus had three subteams: site management, synthesis management and finance, infrastructure and personnel management. It should be noted that the original text of the ISO standards was discussed only in this project management team.

The heads of quality and environmental management and their secretaries also assisted the project team.

\subsection{Strategic Phase}

Assisted by a consultant, we had a oneday training seminar on the philosophy of process management which was attended by all members of site management. The parameters of the business processes were fixed (Fig. 2). In the design phase all members of site management worked together with the subteam leaders and the overall co- ordinator for the three groups. They were divided up according to their responsibility in the organization. At four meetings between February and April 2001 each group discussed its processes as regards input, output, targets, content and interfaces. The proposed process approach was optimized and adopted. Finally, the business processes concept was adopted and supported by site management.

\subsection{Operational Phase}

From May 2001 the operational phase was launched with a two-day introductory training session to bring all members up to the same level. We formed three project subgroups. Each team included one person each from the quality, environmental and production departments (Fig. 3). The heads of the quality and environmental departments were the sponsors, supported by the whole site management. One day in the week was designated the project day. The teams all met together in the morning for a 30-minute briefing. Afterwards detailed work was done in the three groups, including areas of work requiring the agreement of more than one group. The same day after lunch they worked in small groups to specify details of the process descriptions. The project management team met the next morning to discuss all the results and to draw up plans for the following week. Three months proved long enough to agree the details of each process description. The first and last one - as in the old system was the document management process. By November 2001 all 21 business processes had been described. By December all interfaces had been coordinated.

\subsection{Finishing Phase}

From January until the certification audit in early March 2002, the members of the project team helped reorganize documents in line with the new business processes. After the certification audit - which lasted three days - we got a very good rating from the inspectors for our well-integrated management system.

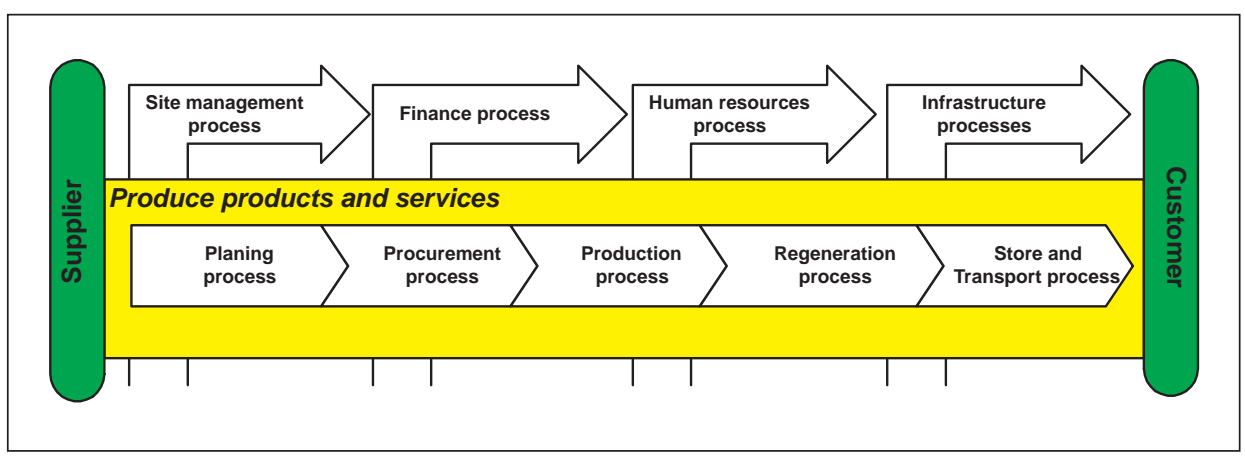

Fig. 2. The overall view of the processes

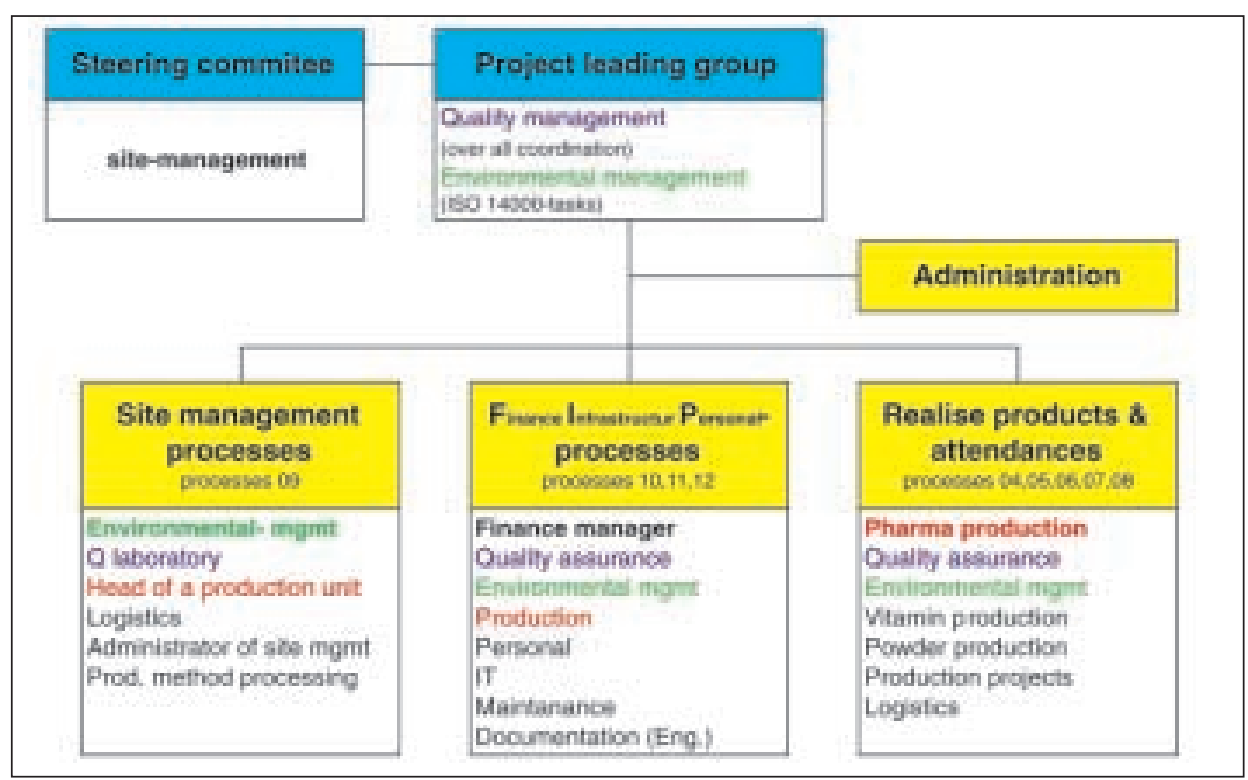

Fig. 3. Project organization in the operative phase 


\subsection{Information and Training}

Throughout the project we reported our progress in the quarterly on-site newspaper. We had to avoid alarming the staff, so no organizational changes were planned in parallel. In June/July 2001 we informed middle management about the new philosophy in processes at a 2-hour briefing; this was followed by a half-day workshop held in each department supported by the project management team on the question 'Where does my work fit into the business process map?'. Each supervisor then explained the new philosophy in processes to his colleagues.

A second 2-hour briefing was held in November 2001. It described how to read the process descriptions, how to follow the standard operating procedures and explained the new numbering system for documents. Another half-day workshop in each department was devoted to the renaming of the SOPs and the elimination of duplicates.

In February 2002 - just before the certification inspection - we put together the most important facts in a flyer, a copy of which was given to all employees by their supervisor.

\section{The Integrated Process Management System}

We limited the documentation structure to three levels: handbook, process descriptions and standard operating procedures.
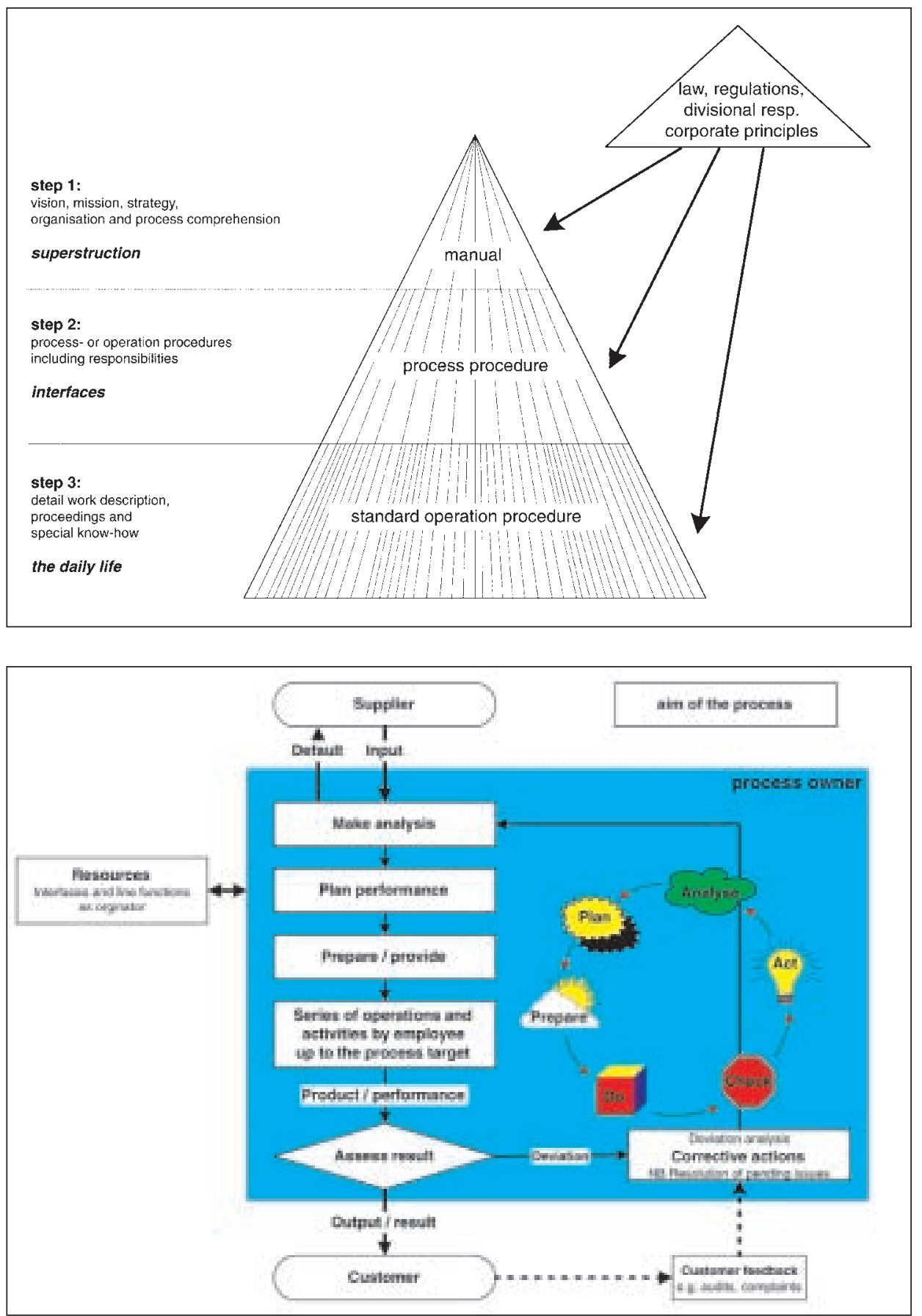

Fig. 4. Document triangle

This traditional approach is still best suited to divisional guidelines, laws and strategic proceedings (Fig. 4).

The management handbook describes administrative aspects in the first chapter. This is followed by a description of the site and its organization, including its mission, vision, an outline of its strategy and its 5 -year targets. The main laws and regulations which have to be complied with are listed for the various sections responsible for personnel, quality, environment, safety, etc. Our definition of processes and a strategic description of the processes form the last chapters of the handbook.

\subsection{The Definition of a Process}

A process is a connected series of actions. Starting from 'input', it passes through the black box of 'the process' and the 'output' achieves the target. If there is a clear picture of the target it is easy to define the input factors. Each process is shown as a circle to reflect continuous improvement and consists of six steps: analyze, plan, prepare, do, check, act (Fig. 5). 
Nevertheless, it was not easy to limit the description of a process to a six-step flow chart. Site management process No. 09.00 is shown as an example (Fig. 6).

An awareness of laws, regulations, standards and corporate principles is needed. It is also important to have a basic understanding of the resources such as personnel and money that are needed to achieve the aim of the process. That aim is always the justification for and focus of each process.

Mention the fact that output must always have a greater value than input. Mention the risks in the ongoing process but use them as an opportunity to optimize it, not merely to correct deviations. Actions of this kind can be used to improve a process and make it more straightforward.

\subsection{Definition of Responsibilities}

Responsibilities are laid down in the process procedures. We adopted the 'DEBI' matrix, which allows tasks to be assigned clearly:

Doer: Person responsible for carrying out a qualitative operation within a specified time and budget

Enforcer: Person who takes and has overall responsibility for basic decisions. Only one person can have this task in each step.

Brainstormer: Consultant who helps to find solutions for problems and to produce decisions. The solution must be arrived at by consensus with the person who has to take the decision; the team aspect is important here.

Informer: People must be informed about decisions made, about a finalized action or a result.

Do not use common organizational abbreviations or people's names. It is always better to specify common functions as the point of contact, such as 'shift leader in production department', 'head of quality control', 'head of transport', 'production administrator', etc.

\subsection{Process Owner Rule}

A common interpretation of this is that the process owner has the task of keeping the process on target and initiating improvements. In an organization where process management coexists with line management, it is not always easy to see and accept the differences (Table).

\subsection{Process Group: Main Processes: Produce Products and Services}

As production site in the Vitamins division of the overall Roche Holding we are part of the 'supply chain process'. This is the basis for our work and the target on

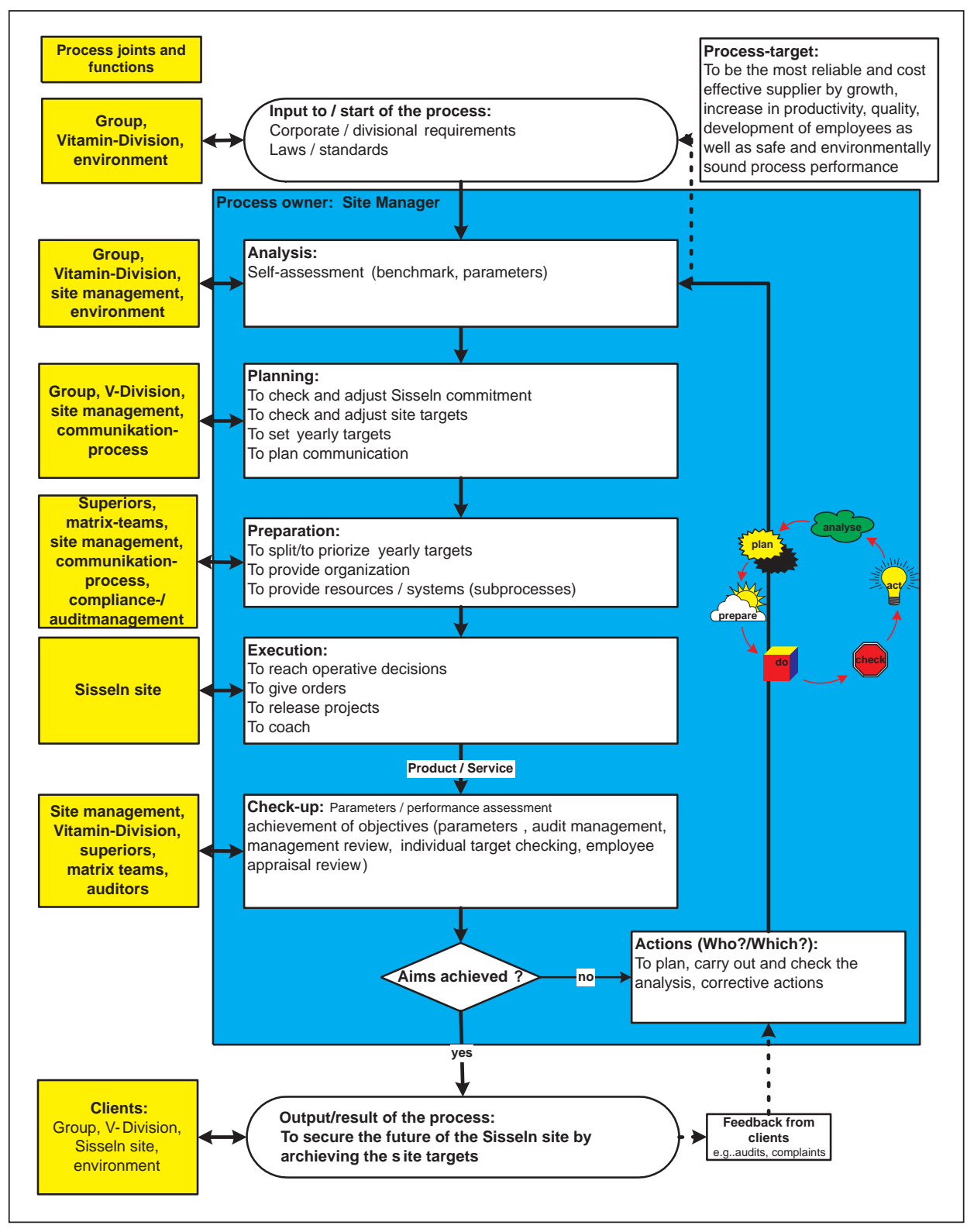

Fig. 6. The PDCA-approach for the site management process

Table. Character of line and process responsibility

\begin{tabular}{ll} 
Line manager & Process owner \\
\hline Site strategy & Process strategy \\
\hline Business responsibility: & Management of the process: \\
- daily business & - optimization of process cycle \\
- legal responsibility & - collecting points for improvement \\
- definition of and changes to SOPs & - setting up matrix teams \\
& - administration (ISO manual, \\
& process procedures) \\
\hline Management responsibility: & Process responsibility: \\
- resources & - time frame for process cycle (DEBI) \\
- staff decision & - resource requirements of line management \\
- ensure that process is put into practice & - training to ensure competence: process \\
- training to ensure competence in & cycle and content \\
business tasks (SOP) & - log and communicate key data \\
\hline Financial responsibility: & Consultant: \\
- budget decisions & - identify and strengthen important \\
& weak points \\
\hline
\end{tabular}


which Roche Ltd, Sisseln stakes its name. This main process has different subprocesses on the way from the supplier to the customer (Fig. 7).

\subsection{1 and 04.02 Planning Processes for Vitamins and Pharma}

At the beginning of our business we need a good means of planning when and how much of our products to synthesize. This is the only process where we have to differentiate between Vitamins and Pharma (including third-party business). There are different ways and means of arriving at the production plan. In the vitamin business we have direct contact with headquarters and for the Roche Pharma business we have to work as a third-party contractor.

Meanwhile it has been officially announced by the Roche Holding that new strategic options outside Roche are being investigated for the Vitamins division. Looking at our business processes, we grouped Pharma planning together with third-party production. This specific case shows the flexibility of the system: such a significant change can be made without altering our on-site management system. We merely have to update the process procedures with new addresses.

The tasks of these processes are:

- coordination of site-wide production

- coordination with divisional and thirdparty planners

- planning of time, quantity and costs for procurement, production, storage and dispensing
- planning of equipment usage per production train

The process is driven by line management.

\subsection{Procurement Process}

The procedure for the procurement of starting materials, solvent, packaging materials, technical equipment, services and capital goods is described in this process flow. It also includes the certification and rating of suppliers, including the actual procurement stage subject to commercial and legal contracts, the checks made when goods are delivered, and stock control. Complaint management for incoming goods and the management of accounts is also part of this process.

\subsection{Production Process}

At the beginning there was a long discussion about whether we would have to separate this process for the Vitamins and Pharma business, given that the legal requirements governing the production of foods and sterile antibiotics are quite different. We have found, however - and only a few people believed this at first - that the way to proceed is in fact the same. The difference is in the detail: more in-depth validation documentation, close involvement of quality control and signature of all documents by quality assurance.

This process therefore includes:

- production of vitamins, animal feed and food products or premixes, including dispensing

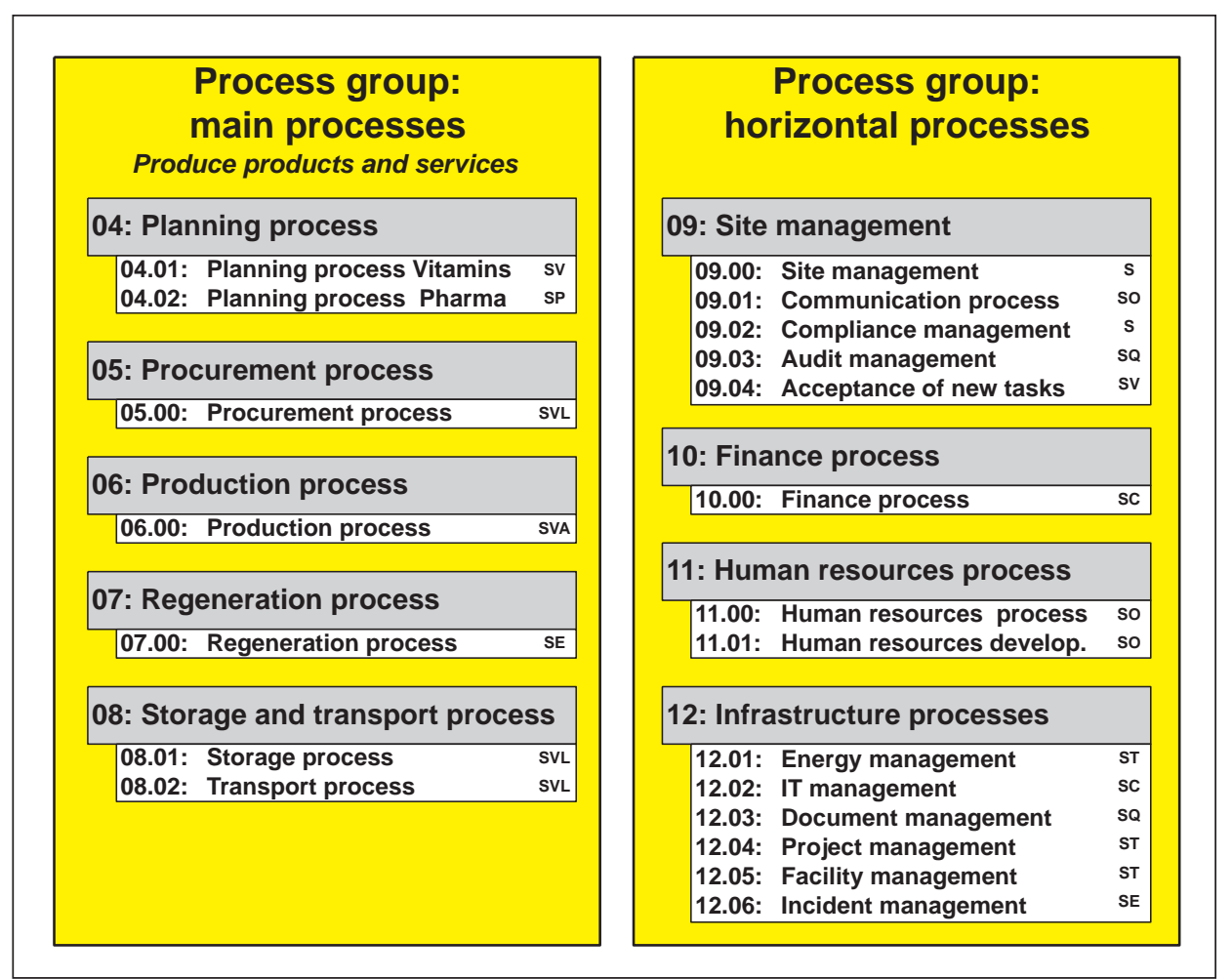

- organization of production, with shift planning and management, process validation and time management

- advances in and the continuous improvement of production and operating procedures

- production supervision including sampling, IPC and QC analyses, deviation handling, cost control

- equipment maintenance with change control, fault correction, calibration, preventive maintenance, engineering support

- documentation of production campaigns, year-end reports, annual product reviews, changing consumption, etc. - solvent regeneration, treatment of waste We had a long discussion about the dividing line between production and regeneration processes. We believe the point is that 'waste' is not directly involved in production, so that solvent recovery is part of the production process, whereas wastewater treatment is part of a regeneration process.

\subsection{Regeneration Process}

Starting with air pulsation in production and waste-water treatment, the regeneration process describes all operational recycling tasks. The regeneration of by-products and waste is an opportunity to treat the waste and consider external recycling. Airpulsation cleaning and waste-water treatment and the incineration of waste and sludge are described as maintenance measures. Analyses of environmental parameters and annual reports are included. 


\subsection{Storage Process}

Covers sampling and analyses of all incoming goods, all kinds of storage in special warehouses, and production areas. Sales and accounting are also part of this process.

\subsection{Transportation Process}

The transport process covers all kinds of transportation from point $\mathrm{A}$ to point $\mathrm{B}$. Transportation of starting materials, goods, technical articles, waste and persons by rail, car, bicycle, fork-lift truck, etc. are included. The target is to avoid damage to goods and injuries to persons.

\subsection{Process Group: Horizontal Processes}

All processes which support the main processes are classified as horizontal processes.

\subsection{Site Management}

This process shows our strategic site management. The main process is numbered 09.00 and additional subprocesses describe organizational tasks in more detail. The way we decide on organizational details and set targets each year is the content of the main 'site management' process. We found that four additional strategic subprocesses are needed to set objectives and to manage the site. It was very difficult to describe them in isolation from operational tasks.

\subsection{Communications Management}

This integrates the concepts of verbal communication, communication by line management, informative meetings and employee motivation. Communication outside the site with the divisions and with public and regulatory bodies is also described.

\subsection{Compliance Management}

Most of the discussions we had to deal with were in compliance management. It was a great step forward to agree that there is no need for separate 'quality', 'waste', 'environment' or 'safety' processes. We found that each time we tried to describe a process we could insert the word 'quality', 'environmental' or 'safety' without changing the process description.

This process thus deals only with the strategic aspects of complying with laws and decrees, co-ordinating matrix teams in the pursuit of different objectives, preparing training materials, programs and running projects on quality, the environment and safety. Assisting internal customers in getting approval from authorities and in preparing annual reports is another major task.

\subsection{Audit Management}

It is not a different process doing audits for financial, quality, environmental or personnel reasons or in response to incidents. It has been a great advantage having a single-handed audit management with just one list of pending issues for line management. Combined audits reduce the time spent by auditors on individual aspects.

\subsection{4 'Acceptance of New Tasks' \\ Process}

Given that the aim is to bring new products, new equipment and new services to the site, this process is helpful and describes the way forward to new growth.

\subsection{Finance Process}

The ISO standards don't require anything like a finance process. However, no company can exist if its finances are not in good order. From the quality point of view this is also an important means of controlling costs and ensuring financial efficiency. We describe the budgeting process, financial stock control, creditors/debtors, financial control and accountancy.

\subsection{Human Resources Process}

Relations between ' $m e$ and my compa$n y^{\prime}$ are covered by the human resources process. It begins with personnel requirements and describes hiring and maintaining employees until their employment ends when they retire or move to another company, and includes the support provided by the human resources department.

\subsection{Human Resources Development Process}

Since this is part of the human resources process, we made it a separate subprocess because departments outside Sisseln are involved. The annual performance appraisal and discussion of welfare interests are part of this process. Target-setting includes more than the well known 'training process'. Nevertheless, methods of training inside, outside and on the job are included.

\subsection{Infrastructure Processes}

This is a collection of all other operational tasks with no direct influence on the supply chain process. There is no overall process procedure for this; only subprocesses are described.

\subsection{Energy Management}

Procurement, availability, consumption analysis and all kinds of energy saving is the task of this process. The energy types are: gases, water, steam, cold media, oil, brine, liquid ammonia, electricity, etc.

\subsection{IT Management}

Different parts are included in IT management: PC-LAN as the standard desktop PC, SAP support activities, laboratory information management system (LIMS) and automatic systems, equipment control and the frequently used user-generated databases and spreadsheets.

\subsection{Document Management}

Document handling, document numbers and many details of corporate and internal identity are described in this process, which is always controversial. Full administrative and other details of our different tasks on the site are given in this part.

\subsection{Project Management}

All kind of investment projects are managed in the project management process. GMP recommendations such as the zone concept, qualification and hygiene tasks are also included in this process.

\subsection{Facility Management}

All infrastructure such as buildings, services (internal postal service, housekeeping, site security and access control) are included in this part.

\subsection{Incident Management}

What we do if something happens. This is the task of incident management. This might be an accident, an incident or a fire. Starting from things with at most only minor consequences, a description is given of the role played by the fire brigade and the site management in major incidents affecting the whole site ('emergency management'). Medical equipment is also included here.

\subsection{The Symbol for our Process Management System}

The symbol of Roche Ltd Sisseln is the water tower in the north of the site. The five main processes form the column and the four rings around it show how the horizontal processes connect with and utilize it (Fig. 8).

\section{Overall Results}

The outline of expenditure, costs and results leads us to conclude that we would choose the same solution again.

\subsection{Personnel Expenditure}

After initiation by the site management (3 person/months), detailed work on the project was done by the project leader (6 person/months), the three subteam leaders (13 person/months) and the other team 


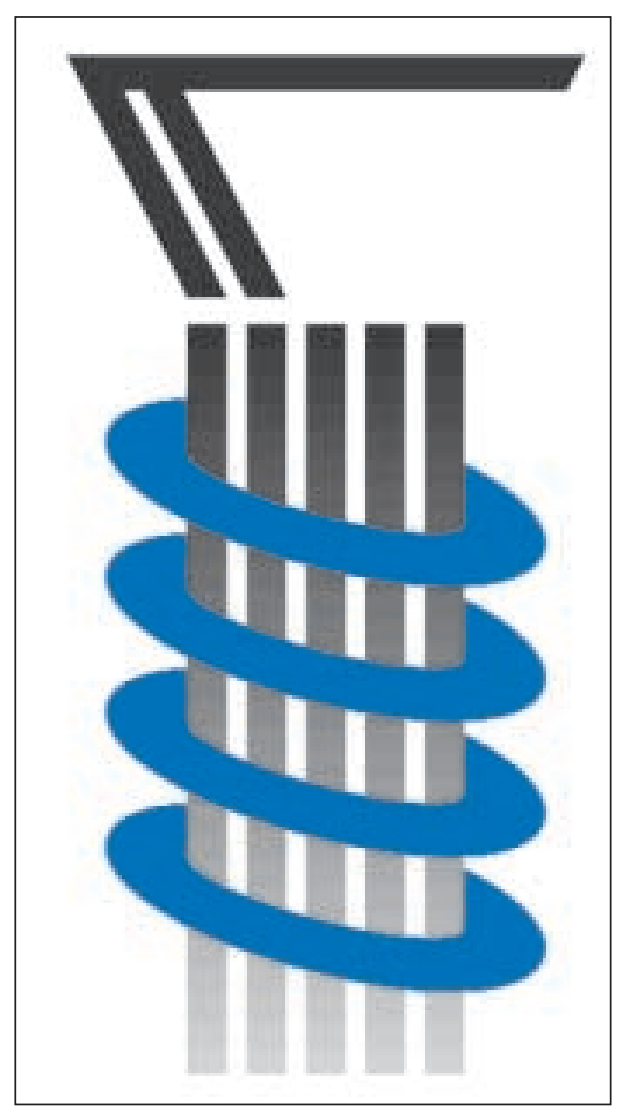

members ( 22 person/months). Overall, the implementation of a process-oriented management system took 12 months or 4 person/years.

\subsection{Cost Management}

We spent CHF 50,000.00 on this noninvestment project, including the training given by a consultant at the beginning, the logo and flyer and all administrative costs for external workshops.

\subsection{Lessons Learned}

Afterwards we found the project organization to be an ideal means of achieving our ambitious project goals. We had clear project objectives, a clear time frame and milestones. Early involvement of site management was a key factor in our success. The new management system therefore supports the change of philosophy. It is a forward-looking process that offers a cumulative solution and has positive matrix effects for line management.

It has been a change which has not affected line management but which has brought about a change in philosophy. If the organization is not effective, the change might be process-oriented. It must however have an effect in reducing costs through greater efficiency.

It was vital to have a core team to coordinate and provide leadership in critical phases of the project. Having dedicated 'project days' facilitated time management by members of the project team.
Fig. 8. Our process logo

\subsection{Benefit for a Manufacturing Site}

Our work involves the synthesis of vitamins and active pharmaceutical ingredients. So far, compliance with ISO standards has only been a secondary concern in our business. Analyzing and optimizing internal and external interfaces has been the goal. A feeling of all belonging to one group and of having a target for our site emerged in line management. A better understanding of processes and overall targets as well as the advantages of matrix teams is the result. This is an opportunity to continuously improve attitudes in preparation for the next steps in optimizing the organization to face the challenges ahead.

\section{Acknowledgements}

I would like to thank Mr. R. Schill, M. Matthes and Dr. W. Jucker for their assistance with this article and the whole site-wide project team working on the details of our system, especially the project team leaders: Dr. M. Glauser in Regeneration, Mr. Th. Günther in Controlling, and Mr. G. Haslimeier in Production.

Received: August 20, 2002

[1] EN ISO 9001 Quality management systems - Requirements (ISO 9001:2000), Swiss Standards Association, 15.12.2000.

[2] EN ISO 14001 Environmental management systems - specification with guidance for use (ISO 14001:1996), Swiss Standards Association, 01.01.1997. 